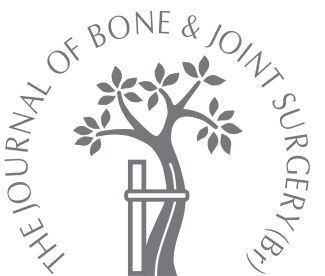

P.-C. Shen,

T.-C. Chern,

K.-C. Wu,

T.-W. Tai,

I.-M. Jou

From the National Cheng Kung

University, Tainin

City, Taiwan

\title{
The assessment of the ulnar nerve at the elbow by ultrasonography in children
}

We evaluated the morphological changes to the ulnar nerve of both elbows in the cubital tunnel by sonography in a total of 237 children, of whom 117 were aged between six and seven years, 66 between eight and nine years, and 54 between ten and 11 years. We first scanned longitudinally in the extended elbow and then transversely at the medial epicondyle with the elbow extended to $0^{\circ}$. We repeated the scans with the elbow flexed at $45^{\circ}, 90^{\circ}$, and $120^{\circ}$. There were no significant differences in the area of the ulnar nerve, but the diameter increased as the elbow moved from extension to flexion in all groups. More importantly, the ulnar nerve was subluxated anteriorly on to the medial epicondyle by $\mathbf{1 . 5 \%}$ to $1.9 \%$ in extended elbows, by $5.9 \%$ to $7.9 \%$ in those flexed to $45^{\circ}$, by $40.0 \%$ to $44 \%$ in those flexed to $90^{\circ}$, and by $57.4 \%$ to $58.1 \%$ in those flexed to $120^{\circ}$, depending on the age group. Sonography clearly and accurately showed the ulnar nerve and was useful for localising the nerve before placing a medial pin. Because the ulnar nerve may translate anteriorly onto the medial epicondyle when the elbow is flexed to $90^{\circ}$ or more, it should never be overlooked during percutaneous medial pinning.

\begin{abstract}
P.-C. Shen, MD, Orthopaedic Surgeon

Department of Orthopaedic Surgery

Tainan Hospital, Department of Health, Executive Yuan, No. 125, Jhongshan Road, Tainin City, 700 Taiwan.

T.-C. Chern, MD, Orthopaedic Surgeon

Chern Tai-Chung's

Orthopaedics Clinic, No. 370,

Boai Road, Ping-Tong City, 900

Taiwan.

K.-C. Wu, MD, Orthopaedic Surgeon

Department of Orthopedics Kuo's General Hospital, No. 22 Sec. 2, Minsheng Road, Tainin City, 700 Taiwan.

- T.-W. Tai, MD, Orthopaedic Surgeon

I.-M. Jou, MD, PhD, Professor Department of Orthopedics National Cheng Kung University, College of Medicine, No. 138 Sheng Li Road, Tainin City, 704 Taiwan.

Correspondence should be sent to Professor I.-M. Jou; e-mail: jming@mail.ncku.edu.tw

C2008 British Editorial Society of Bone and Joint Surgery doi:10.1302/0301-620X.90B5 $19820 \$ 2.00$

$J$ Bone Joint Surg $[B r]$ 2008;90-B:657-61.
Received 14 June 2007 Accepted after revision 24 January 2008

Supracondylar fracture of the humerus is common in children. Closed reduction using a percutaneous crossed Kirschner (K-)wire is a common method for treating displaced fractures. Because the ulnar nerve is close to the point of insertion and the pathway of medial pinning, and an inability to feel the ulnar nerve in a very swollen elbow makes insertion of the wire essentially a 'blind' technique, this nerve is at risk even in experienced hands. ${ }^{1-5}$ Accurate localisation of the point of insertion and full palpation of the ulnar nerve are essential to prevent iatrogenic injury, ${ }^{6}$ but palpation alone cannot provide the surgeon with a comprehensive anatomical picture. ${ }^{3}$ Until now, closed reduction with fixation by only a lateral pin, ${ }^{7-9}$ medial pinning after visualising the ulnar nerve via a small incision, ${ }^{9-12}$ or localising the ulnar nerve using intra-operative stimulation ${ }^{3,13}$ have been advocated to decrease the risk of injury.

In the past few years, high-resolution ultrasonography of peripheral nerves has increased in importance. ${ }^{14}$ This non-invasive technology which does not use radiation makes it possible to view the unossified epiphysis ${ }^{15}$ and the ulnar nerve. ${ }^{14,16}$ We have used this technique to evaluate the morphology of the ulnar nerve and measure its movement in children. We tested the hypothesis that sonography allows direct intraoperative visualisation of the ulnar nerve, the
\end{abstract}

cubital tunnel and adjacent structures and may assist in localising the ulnar nerve before placing the medial pin. High-resolution sonography was used to evaluate the morphological changes in the ulnar nerve in the cubital tunnel, in different positions of the elbow in children, and to define its relationship to the medial epicondyle.

\section{Patients and Methods}

There were three groups of children totalling 237; 117 were aged between six and seven years, 66 between eight and nine years and 54 between ten and 11 years. All had undergone a routine annual health examination provided by the healthcare unit of one local elementary school. The enrolment criteria were no known history of trauma or pathological condition of the limbs, especially the elbows. This study was approved by the Institutional Review Board of the National Cheng Kung University Hospital.

Examination of the range of motion of the wrists, elbows, and shoulders of all the children were carried out by one senior orthopedic surgeon (T-CC). Then, both elbows of all participants were sonographically examined by another senior orthopaedic surgeon (I-MJ) with more than ten years' experience in musculoskeletal sonography. Both examinations were done using high-resolution ultra- 


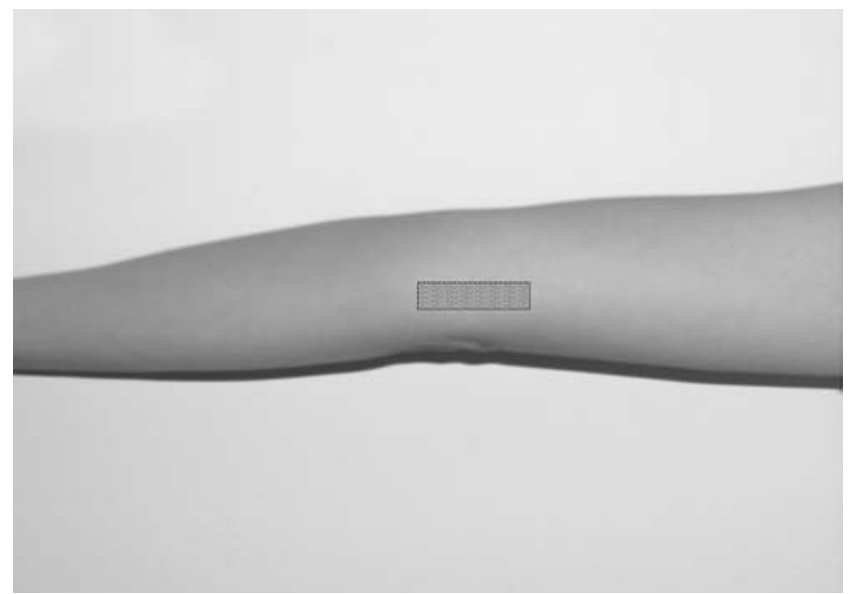

Fig. 1a

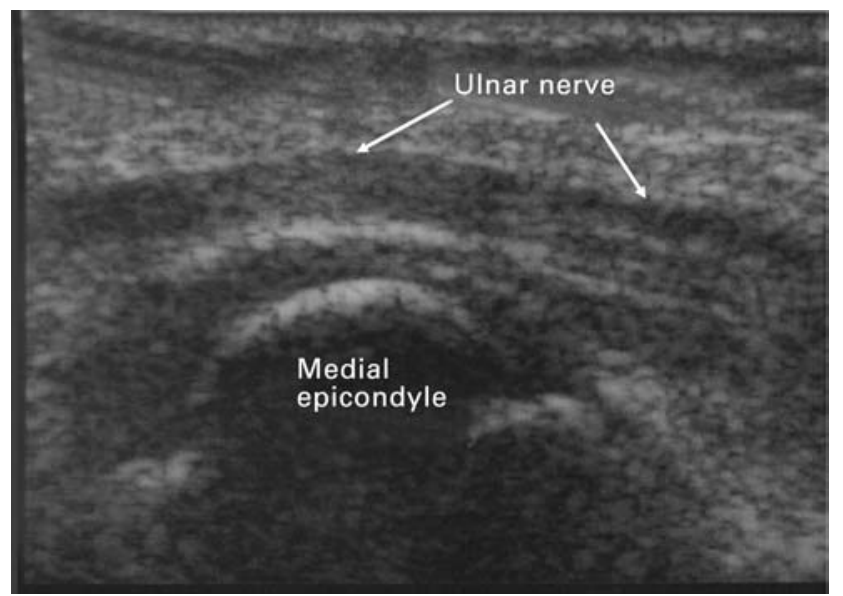

Fig. 1c

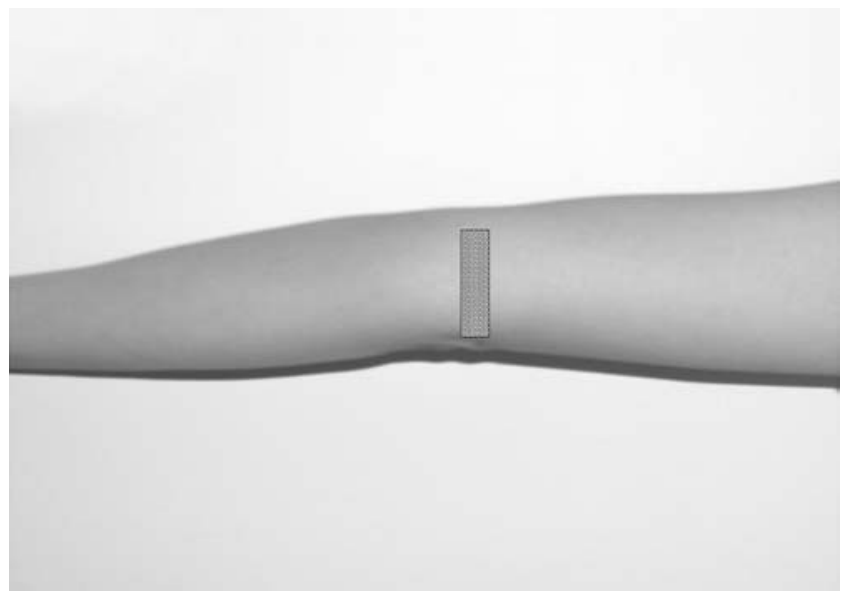

Fig. 1b

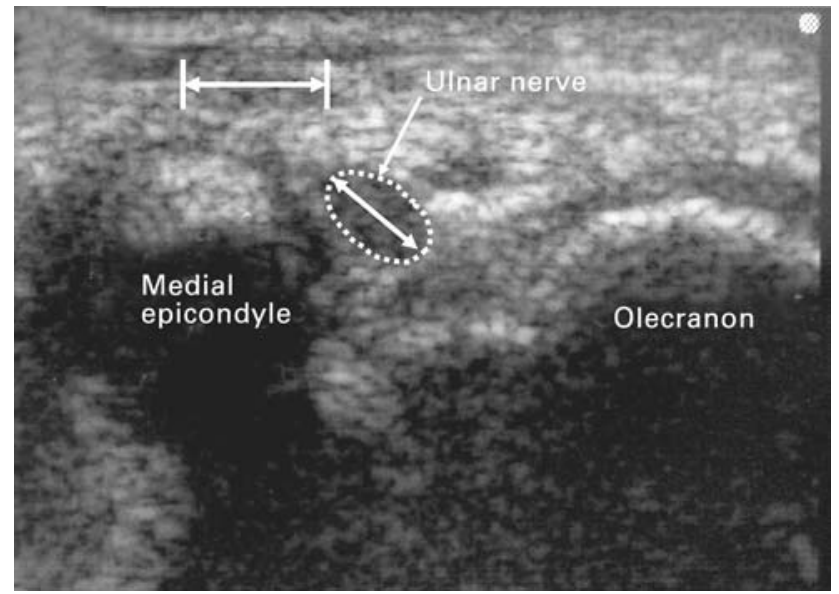

Fig. 1d

Photographs showing the positions of the transducer, and the corresponding sonograms, for the longitudinal (a, c) and transverse (b, d) sections. The sonograms reveal characteristic echoic reflections with an echogenic perineurium surrounding the hypoechoic ulnar nerve, and the bright echogenic border of the medial epicondyle and olecranon with a typical acoustic shadow from the longitudinal and transverse sections (arrows), outlined using the direct area measurement tool. The diameter of the ulnar nerve (double-ended arrow within dotted white oval), the cross-sectional area of the nerve (outlined oval), and the distance between the medial epicondyle measured for analysis in transverse section (double-ended arrow within vertical bars) can all be seen.

sonography with a $5 \mathrm{MHz}$ to $10 \mathrm{MHz}$ linear-array transducer (SonoSite Inc., Bothell, Washington). The child was seated facing the examiner. The shoulder of the examined limb was placed in $60^{\circ}$ of flexion and externally rotated to $90^{\circ}$. The wrist was held by an assistant. Sonographic examination of the ulnar nerve was carried out with the elbow extended and at $45^{\circ}, 90^{\circ}$ and $120^{\circ}$ of flexion. The ulnar nerve was first examined in parallel on longitudinal images identified using the palpable bony landmarks of the cubital tunnel of the extended elbow. The morphology and dynamics of the nerve were then assessed on transverse images strictly perpendicular to the axis of the nerve at the cubital tunnel of the medial epicondyle (Figs 1a and 1b). The diameter and cross-sectional area of the ulnar nerve were measured at the different angles. The distances between the ulnar nerve and the tip of the medial epicondyle of the transverse images were marked, measured in the various positions of the elbow and calculated using a direct trace and ellipse tool provided by the high-resolution ultrasonography used in this study.

We used a paired $t$-test to compare the differences between the right and left sides of the elbow. We used oneway analysis of variance (ANOVA) to analyse the differences in the same parameter in the same position between the three different age groups and in the same age group between the four different positions of the elbow. Statistical significance was set at $\mathrm{p}<0.05$. The values are given as means. 
Table I. Demographic data of the participants in the study

\begin{tabular}{|c|c|c|c|c|}
\hline & \multicolumn{4}{|l|}{ Age (yrs) } \\
\hline & 6 to 7 & 8 to 9 & 10 to 11 & Total \\
\hline Total & 117 & 66 & 54 & 237 \\
\hline \multicolumn{5}{|l|}{ Gender } \\
\hline Female & 48 & 33 & 27 & \\
\hline Male & 69 & 33 & 27 & \\
\hline Mean age in yrs (range) & $7.0(6.0$ to 7.9$)$ & 9.5 (8.0 to 9.9 ) & $11.8(10.0$ to 11.9$)$ & \\
\hline Mean height in $\mathrm{cm}$ (range) & $120.0(106.0$ to 126.0$)$ & $131.0(116.0$ to 143.0$)$ & $144.0(119.0$ to 162.0$)$ & \\
\hline Mean weight in kg (range) & 23.6 (15.0 to 33.0$)$ & $30.6(16.0$ to 58.0$)$ & $41.6(22.0$ to 67.0$)$ & \\
\hline \multicolumn{5}{|c|}{ Mean diameter of the ulnar nerve in $\mathrm{mm}$ (range) ${ }^{*}$} \\
\hline At $0^{\circ}$ (extended) & $3.1(1.7$ to 4.2$)$ & $3.8(2.0$ to 4.7$)$ & $4.0(2.3$ to 5.7$)$ & \\
\hline At $45^{\circ}$ of flexion & $3.2(2.0$ to 4.9$)$ & $3.9(2.6$ to 4.8$)$ & $4.3(2.3$ to 5.6$)$ & \\
\hline At $90^{\circ}$ of flexion & $3.9(1.8$ to 7.8$)$ & $4.2(2.5$ to 6.8$)$ & $5.0(3.1$ to 8.6$)$ & \\
\hline At $120^{\circ}$ of flexion & $4.5(2.0$ to 6.6$)$ & $5.4(2.4$ to 8.7$)$ & $6.0(2.7$ to 7.7$)$ & \\
\hline \multicolumn{5}{|c|}{ Mean nerve area in $\mathrm{mm}^{2}(\text { range })^{\dagger}$} \\
\hline At $0^{\circ}$ (extended) & $4.0(2.0$ to 7.0$)$ & $4.9(3.0$ to 6.0$)$ & 5.7 (3.0 to 8.0$)$ & \\
\hline At $45^{\circ}$ of flexion & $4.0(2.0$ to 7.0$)$ & $5.0(2.0$ to 7.0$)$ & $5.9(4.9$ to 9.0$)$ & \\
\hline At $90^{\circ}$ of flexion & $4.1(2.0$ to 6.0$)$ & $5.0(2.0$ to 7.0$)$ & $6.0(3.0$ to 8.0$)$ & \\
\hline At $120^{\circ}$ of flexion & $4.3(2.0$ to 7.0$)$ & $5.1(3.0$ to 8.0$)$ & $6.0(3.0$ to 8.0$)$ & \\
\hline \multicolumn{5}{|c|}{$\begin{array}{l}\text { Mean distance between ulnar nerve and medial epicondyle in } \mathrm{mm} \\
\text { (range })^{*}\end{array}$} \\
\hline At $0^{\circ}$ (extended) & 4.5 (2.5 to 6.6$)$ & $4.4(0.0$ to 6.2$)$ & $5.0(1.6$ to 7.1$)$ & \\
\hline At $45^{\circ}$ of flexion & $3.3(0.0$ to 5.5$)$ & $2.8(0.0$ to 4.5$)$ & $3.3(0.0$ to 6.5$)$ & \\
\hline At $90^{\circ}$ of flexion & $1.7(-1.8$ to 4.7$)$ & $1.3(-1.2$ to 3.4$)$ & $1.7(-3.6$ to 5.3$)$ & \\
\hline At $120^{\circ}$ of flexion & $0.8(-5.4$ to 2.7$)$ & $0.9(-1.7$ to 3.3$)$ & $1.2(-5.6$ to 3.7$)$ & \\
\hline \multicolumn{5}{|c|}{ Percentage of ulnar nerve translated onto medial epicondyle $(\mathrm{mm})^{\ddagger}$} \\
\hline At $0^{\circ}$ (extended) & 1.7 & 1.5 & $1.9(p=0.990)$ & 1.6 \\
\hline At $45^{\circ}$ of flexion & 5.9 & 6.0 & $7.9(p=0.018)$ & 6.3 \\
\hline At $90^{\circ}$ of flexion & 40.1 & 40.0 & $44.0(p=0.421)$ & 40.9 \\
\hline At $120^{\circ}$ of flexion & 58.1 & 57.6 & $57.4(p=0.995)$ & 57.9 \\
\hline
\end{tabular}

\section{Results}

Baseline characteristics of the children. There were no significant differences between the groups except for a normal increase in body weight and height in the older age groups (Table I). Of the 237 children, 45 (19\%) were left-handed and 192 (81\%) right-handed.

Sonographic anatomy of the ulnar nerve and cubital tunnel. The ulnar nerve was examined in both transverse and longitudinal sections (Figs $1 \mathrm{a}$ and $1 \mathrm{~b}$ ) and appeared as a hypoechoic cord-like structure with internal hyperechoic lines, and an underlying bony border with a hyperechoic line with a posterior shadow (Fig. 1c). Similar findings were seen in the longitudinal sections of all participants. In the transverse section (Fig. 1d) at the level of the cubital tunnel, the ulnar nerve appears as an oval-to-round structure of hypoechoic echotexture occasionally with a narrow hyperechoic rim and internal punctuate echoes. The flexor retinaculum encloses the cubital tunnel anteriorly and is seen as a hyper- echoic band which extends from the olecranon to the medial epicondyle.

Sonographic measurement and morphologic change of the ulnar nerve in different positions of the elbow. The sonographic diameter and measurements of the area carried out using a direct trace and an ellipse tool were highly reproducible. There were no significant differences between sides $(p>0.05)$ or gender $(p>0.05)$. For the same position of the elbow, older children had a nerve of larger diameter and area in all three groups. There were significant differences between groups as the diameter of the ulnar nerve increased as the elbow moved from $0^{\circ}$ to $45^{\circ}, 90^{\circ}$, and $120^{\circ}$ of flexion (all, p < 0.001). However, the cross-sectional area of the ulnar nerve in all four positions did not change significantly in any group ( $\mathrm{p}>0.05 ; 6$ to 7 years, $\mathrm{p}=0.466 ; 8$ to 9 years, $\mathrm{p}=0.748 ; 10$ to 11 years, $\mathrm{p}=0.693$ ) (Fig. 2 ).

We found that the ulnar nerve moved anteromedially when the elbow was flexed. This is reflected by the distance 

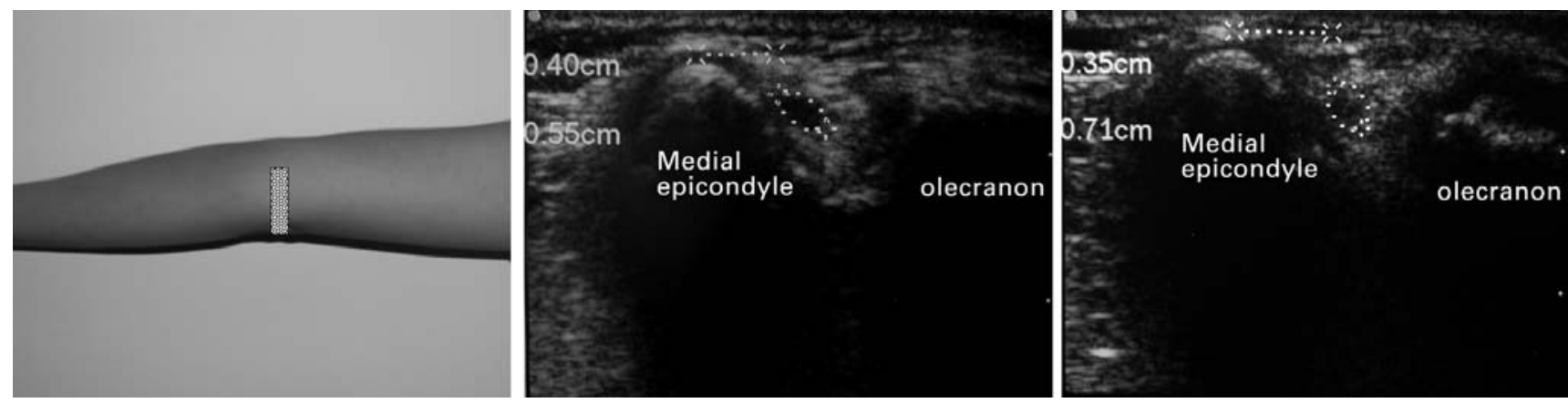

Fig. $2 a$
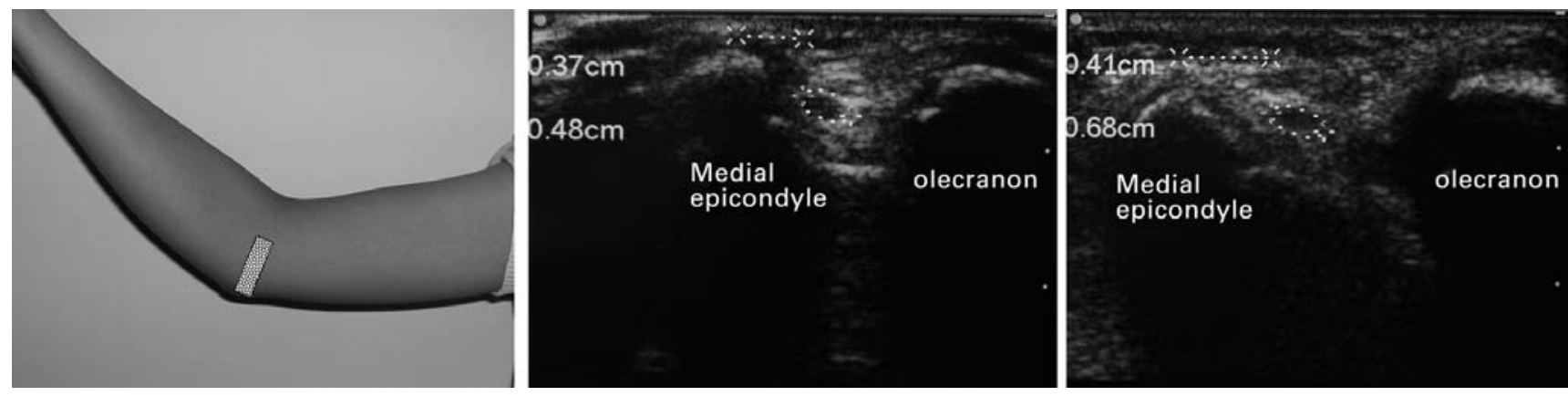

Fig. $2 b$
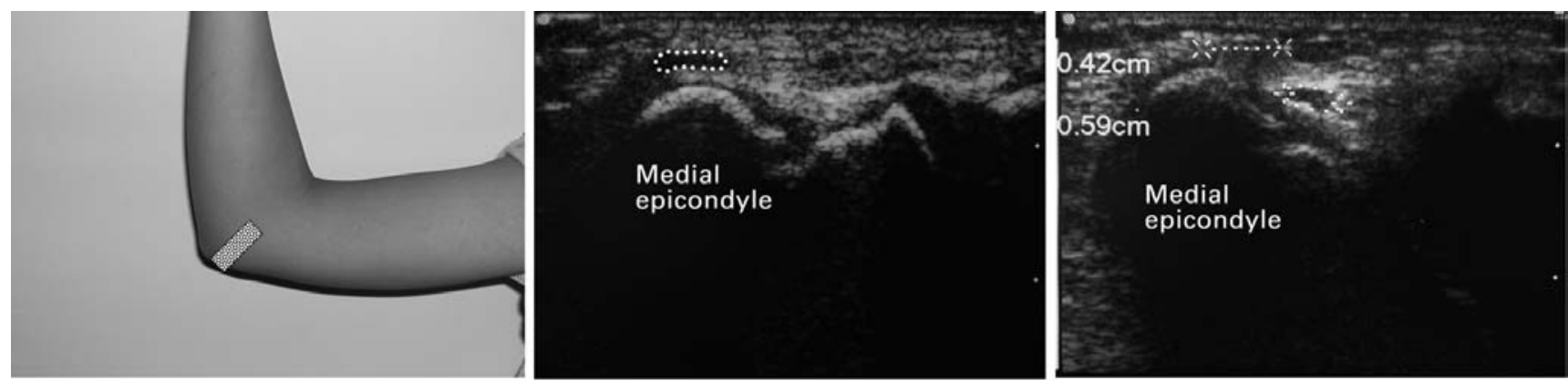

Fig. 2c
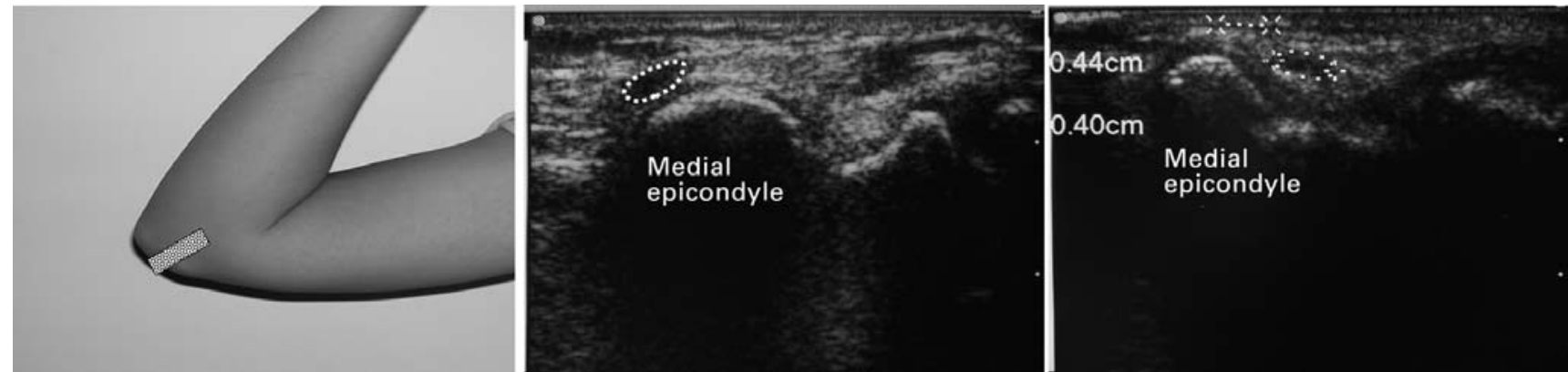

Fig. 2d

Photographs showing the positions of the transducer for transverse views in the four different positions of the elbow a) in extension, b) at $45^{\circ}$ of flexion, c) at $90^{\circ}$ of flexion and d) at $120^{\circ}$ of flexion. The serial sonograms reveal the changes in the diameter, area, and distance between the ulnar nerve and the medial epicondyle in two cases in which the nerve was dislocated (middle column, third and fourth images) and stable (right-hand column).

between the ulnar nerve and medial epicondyle, which decreased significantly from $0^{\circ}$ to $45^{\circ}, 90^{\circ}$, and $120^{\circ}$ of flexion. These differences were statistically significant in all groups (ANOVA, $\mathrm{p}<0.001$ ) (Fig. 2). We found that the ulnar nerve was translated anteriorly to the medial epicondyle in increasing flexion as shown in Figure 2. 


\section{Discussion}

There is no published study dealing with images of the peripheral nerves in children. The well-controlled sonographic examination of the present study verified a consistent change in morphology of the ulnar nerve, with flattening without a change in the area of cross section of the nerve when the elbow was flexed. We found that the distance between the ulnar nerve and the tip of the medial epicondyle decreased consistently and statistically significantly during flexion. Our most important finding was the incidence of translation of the subluxed or dislocated ulnar nerve from the cubital tunnel anteriorly on to the top of the medial epicondyle when the elbow was flexed to $90^{\circ}$ or $120^{\circ}$ in all three groups. We therefore agree with Zaltz, Waters and Kasser $^{17}$ that such a hypermobile nerve may rest anterior to the medial epicondyle during reduction of a fracture and come to lie in the pathway of a medial wire, putting the nerve at risk of significant injury. The nerve must be localised accurately before introduction of a medial pin for fixation of a fracture.

This study showed that high-resolution sonography depicts the exact location and anatomy of the ulnar nerve and the bony border of the cubital tunnel in children aged between six and 11 years. Subluxation of the ulnar nerve in increasing flexion has been recorded in adults. ${ }^{18}$ Only one study ${ }^{17}$ has described instability of the ulnar nerve using palpation while the elbow was flexed and extended in 164 American children between 10 months and 18 years old. Instability of the nerve was positively associated with younger age and ligamentous laxity. These observations, data from a previous study ${ }^{17}$ and our findings of a more flexible retinaculum of the cubital tunnel in children, may account for a higher incidence of subluxation of the ulnar nerve when the elbow is flexed.

Sonography permits real-time (dynamic) and multidirectional observation allowing a more precise, exact, and objective method of defining movement of the ulnar nerve. Clinical studies are required to focus on the identification and clear delineation of the ulnar nerve in a fractured elbow with marked swelling and deformation.
No benefits in any form have been received or will be received from a commercial party related directly or indirectly to the subject of this article.

\section{References}

1. Flynn JC, Matthews JG, Benoit RL. Blind pinning of displaced supracondylar fractures of the humerus in children: sixteen years' experience with long-term follow-up. J Bone Joint Surg [Am] 1974;56-A:263-72.

2. Ikram MA. Ulnar nerve palsy: a complication following percutaneous fixation of supracondylar fractures of the humerus in children. Injury 1996;27:303-5.

3. Wind WM, Schwend RM, Armstrong DG. Predicting ulnar nerve location in pinning of supracondylar humerus fractures. J Pediatr Orthop 2002;22:444-7.

4. Mangwani J, Nadarajah R, Paterson JM. Supracondylar humeral fractures in children: ten years' experience in a teaching hospital. J Bone Joint Surg [Br]2006:88B:362-5.

5. Ramachandran M, Birch R, Eastwood DM. Clinical outcome of nerve injuries associated with supracondylar fracture of the humerus in children: the experience of a specialist referral centre. J Bone Joint Surg [Br] 2006;88-B:90-4.

6. Shim JS, Lee YS. Treatment of completely displaced supracondylar fracture of the humerus in children by cross-fixation with three Kirschner wires. J Pediatr Orthop 2002;22:12-16

7. Kallio PE, Foster BK, Paterson DC. Difficult supracondylar elbow fractures in children: analysis of percutaneous pinning technique. J Pediatr Orthop 1992;12:11-15.

8. Skaggs DL, Hale JM, Bassett J, et al. Operative treatment of supracondylar fractures of the humerus in children: the consequences of pin placement. J Bone Joint Surg [Am] 2001;83-A:735-40.

9. Taniguchi Y, Matsuzaki K, Tamaki T. latrogenic ulnar nerve injury after percutaneous cross-pinning of supracondylar fracture in a child. J Shoulder Elbow Surg 2000;9:160-2.

10. Weiland AJ, Meyer S, Tolo VT, Berg HL, Mueller J. Surgical treatment of displaced supracondylar fractures of the humerus in children: analysis of fifty-two cases followed for five to fifteen years. J Bone Joint Surg [Am] 1978;60-A:657-61.

11. Royce RO, Dutkowsky JP, Kasser JR, Rand FR. Neurologic complications after Kwire fixation of supracondylar humerus fractures in children. J Pediatr Orthop 1991;11:191-4

12. Lyons JP, Ashley E, Hoffer MM. Ulnar nerve palsies after percutaneous cross-pinning of supracondylar fractures in children's elbows. J Pediatr Orthop 1998;18:43-5.

13. Michael SP, Stanislas MJ. Localization of the ulnar nerve during percutaneous wiring of supracondylar fractures in children. Injury 1996;27:301-2.

14. Beekman R, Visser LH. High-resolution sonography of the peripheral nervous system: a review of the literature. Eur J Neurol 2004;11:305-14.

15. Davidson RS, Markowitz RI, Dormans J, Drummond DS. Ultrasonographic evaluation of the elbow in infants and young children after suspected trauma. $J$ Bone Joint Surg [Am] 1994;76-A:1804-13.

16. Okamoto M, Abe M, Shirai H, Ueda N. Morphology and dynamics of the ulnar nerve in the cubital tunnel: observation by ultrasonography. J Hand Surg $[\mathrm{Br}]$ 2000;25:85-9.

17. Zaltz I, Waters PM, Kasser JR. Ulnar nerve instability in children. J Pediatr Orthop 1996;16:567-9.

18. Kim BJ, Date ES, Lee SH, et al. Distance measure error induced by displacement of the ulnar nerve when the elbow is flexed. Arch Phys Med Rehabil 2005:86:809-12. 